\title{
Interactive comment on "Estimation of Evapotranspiration and Other Soil Water Budget Components in an Irrigated Agricultural Field of a Desert Oasis, Using Soil Moisture Measurements" by Zhongkai Li et al.
}

\section{Prof. Shen}

yjshen@sjziam.ac.cn

Received and published: 31 October 2018

General Comments: Accurate assessment of soil water budget components (SWBCs) is necessary for improving irrigation strategies and optimizing the use of fertilizer in agricultural systems. However, quantitative information of SWBCs is usually challenging to obtain. Soil moisture is a variable that integrates the water balance components of land surface hydrology, and thus over time it can be used to develop a record of antecedent hydrologic fluxes. This paper presents an interest and important study on a soil moisture data-driven method for the water budget components estimation. Overall,

Printer-friendly version

Discussion paper 
the research was well conducted, and the whole manuscript was generally well written. I recommend publication consideration, granted that the minor concerns and questions below are properly addressed.

Specific comments: - The abstract is concise and almost complete. The only suggestion is to clarify in line $27-28$ that why the cumulative irrigation volumes varied so much among the 6 different plots, i.e., $652-1186 \mathrm{~mm}$. Although you mentioned that this phenomenon can be largely attributed to the plastic film mulching at the NT1 in your manuscript (Line 351-353), it should also be stressed in your abstract. -Page 2, Line 53-54, ". . irrigating too early", I guess it should be "irrigating too much"? -Page 2, Line 69-70, the citation of the references [(Mcgowan and Williams, 1980) (Koksal et al., 2017)] was not correct due likely to font conversion. -Page 3, Fig. 1c, the root systems of crop and alfalfa drawn by the authors are not good to indicate their real patterns in the soil profiles. In most cases, root distribution with depth is that of a negative exponential function, i.e., (Wasson et al., 2017). -Page 5, Line 165-194, there are more than one method are available to do this calculation, i.e., enhanced soil water balance, slope approach (Guderle and Hildebrandt, 2015), what is the reason for choosing the Inverse Soil Water Flow Model in this paper? -Page 6, Line 206, what kind of software? You mean the codes that you developed to do this calculation? You don't mention it throughout the manuscript. Please clarify this point. -Page 7, Line 246, the citation is not complete, please double check it. -Page 9, Line 287, why you start this part from NT6 rather than NT1, what is the logic behind this? -Page 11, Line 378-381, you mentioned that one of the potential reasons that could result in the different irrigation rates is the mutation of the infiltration rate. If this is the case, how well do the TDR measurements-based estimation of irrigations represent the experimental plots? More related discussions are needed to clarify this point. -Page 12, Line 416-417, "Information on SWBCs is crucial for irrigation planning at both the field and regional scale (Jalota and Arora, 2002), and the best estimates should be based on models of soil water, because direct measurements are not available in most cases", it is better to move
this sentence to the 2nd paragraph in section 4.4., i.e., Line 429. -Page 15, Line 542; ter, because direct measurements are not available in most cases", it is better to move
this sentence to the 2nd paragraph in section 4.4., i.e., Line 429. -Page 15, Line 542;

Printer-friendly version

Discussion paper 
Page 17, Line 619, the references were not organized in the correct style of HESS.

Interactive comment on Hydrol. Earth Syst. Sci. Discuss., https://doi.org/10.5194/hess-2018-

HESSD

518, 2018.

Interactive

comment 